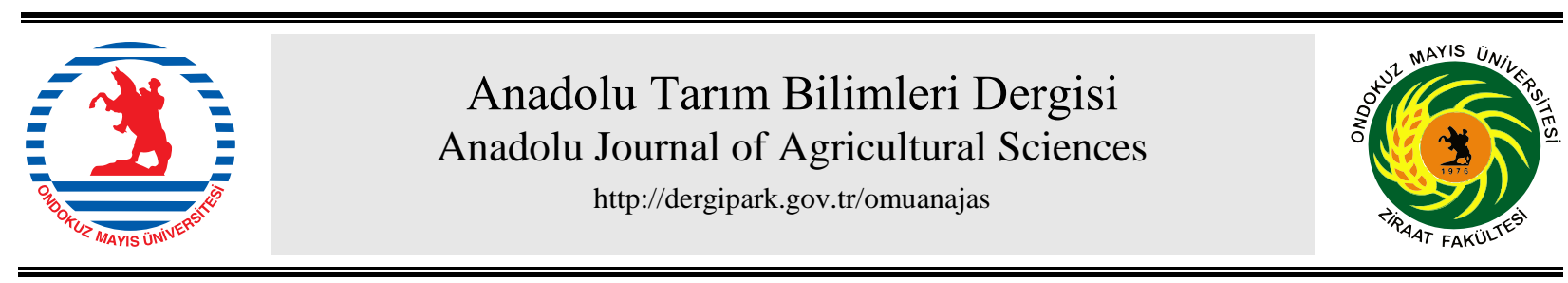

Araştırma/Research

Anadolu Tarım Bilim. Derg./Anadolu J Agr Sci, 34 (2019) ISSN: 1308-8750 (Print) 1308-8769 (Online) doi: $10.7161 /$ omuanajas.541230

\title{
Konvektif ve mikrodalga yöntemlerle kurutulan kuşburnu (RosamontanaChaixsubsp. woronovii (Lonacz) Ö. Nilsson) meyvelerinde kalite değişimleri
}

\author{
Muhammed Taşova $^{\mathrm{a} *}$, Gazanfer Ergüneş $^{\mathrm{a}}$, Resul Gerçekcioğlu ${ }^{\mathrm{b}}$, Şükrü Karagül ${ }^{\mathrm{c}}$ \\ ${ }^{a}$ Gaziosmanpaşa Üniversitesi Ziraat Fakültesi Biyosistem Mühendisliği Bölümü, Tokat \\ ${ }^{b}$ Gaziosmanpaşa Üniversitesi Ziraat Fakültesi Bahçe Bitkileri Bölümü, Tokat \\ ${ }^{c}$ Akdeniz Üniversitesi Elmalı Meslek Yüksekokulu Bitkisel ve Hayvansal Üretim /Bahçe Tarımı \\ *Sorumlu yazar/corresponding author: muhammed.tasova@gop.edu.tr \\ Geliş/Received 18/03/2019 Kabul/Accepted 21/09/2019
}

\begin{abstract}
ÖZET
$\mathrm{Bu}$ çalışmada, 'Gerçekcioğlu' kuşburnu çeşidinin meyvesi kurutularak kuruma süresi, renk ve C vitamin kriterleri açısından en uygun kurutma şartının belirlenmesi amaçlanmıştır. Materyal mikrodalga kurutucuda; 360, 540, 720 ve $900 \mathrm{~W}$ güç değerlerinde ve etüv kurutucuda ise; 50,60 ve $70{ }^{\circ} \mathrm{C}$ kurutma havası sıcaklıkların da kurutulmuştur. Uygulanan mikrodalga güç değerlerinde belirlenen ortalama kuruma süreleri sırasıyla; 27, 14, 11 ve 9 dakika olarak tespit edilirken, etüv de ise sırasıyla; 16.57 .5 ve 7 saat olarak belirlenmiştir. Tazeye göre renk değeri açısından en uygun kurutma şartı mikrodalga kurutucuda $720 \mathrm{~W}$ güç değerinde, etüv kurutucuda ise $60{ }^{\circ} \mathrm{C}$ kurutma havası sıcaklığında yapılan kurutma işlemlerinde belirlenmiştir. Taze kuşburnu meyvesine göre, en fazla kaybolan \% $\mathrm{C}$ vitamini değeri \% 91.36 oranla etüv kurutucuda $60{ }^{\circ} \mathrm{C}$ sıcaklığında ve mikrodalga kurutucuda ise $540 \mathrm{~W}$ güç değerinde hesaplanmıştır. Taze kuşburnu meyvesinin $\mathrm{C}$ vitamin değerine göre, en uygun mikrodalga kurutma şartının $900 \mathrm{~W}$, sıcak havalı kurutma şartının ise $70^{\circ} \mathrm{C}$ olduğu belirlenmiştir.
\end{abstract}

Quality changes in rosehip (RosamontanaChaixsubsp. woronovii (Lonacz) $\ddot{O}$. Nilsson) fruits dryed by convective and microwave methods

\section{ABSTRACT}

.In this study, it is aimed to determine the most suitable drying condition in terms of drying time, color and vitamin $\mathrm{C}$ criteria by drying the fruit of 'Gerçekcioğlu' rosehip variety. The fruits were dried in microwave dryer $360,540,720$ and $900 \mathrm{~W}$ power values. The fruits were dried drying air temperatures of 50,60 and $70{ }^{\circ} \mathrm{C}$ in drying oven. The average drying times determined in the applied microwave power values are as follows 27, 14, 11 and 9 minutes. The average drying times determined in the applied drying air temperatures are as follows 16.5 7.5 and 7 hours. The most suitable drying condition in terms of color value according to freshness was determined at $720 \mathrm{~W}$ power in microwave dryer and $60{ }^{\circ} \mathrm{C}$ drying air temperature in drying oven. According to fresh rosehip fruits, the most lost vitamin $\mathrm{C}$ value was $91.36 \%$ at $60{ }^{\circ} \mathrm{C}$ in convective dryer and $540 \mathrm{~W}$ power in microwave dryer. According to vitamin $\mathrm{C}$ value of fresh rosehip fruit, the most appropriate microwave drying condition was $900 \mathrm{~W}$ and hot air drying condition was $70^{\circ} \mathrm{C}$.

Anahtar Sözcükler: Ürün kurutma Renk Kuruma süresi C vitamini
Keywords: Product drying Color Drying times Vitamin C

\section{Giriş}

Kuşburnu meyvesi (Rosacanina L.) Türkiye'de olduğu gibi birçok Avrupa ülkesinde de yaygın bir şekilde doğal olarak yetişmektedir (Artik ve Eksi, 1988; Demir ve Özcan, 2001; Erentürk ve ark., 2005).
Kuşburnu temelde vitamin $\mathrm{C}$ değeri açısından oldukça zengin olduğu gibi potasyum ve fosfor gibi besin elementlerini de bünyesinde barındırmaktadır. $100 \mathrm{~g}$ kuşburnu meyvesinde ortalama 50-5000 mg vitamini olduğu bilinmektedir. Bununla beraber içerdiği K, P, E vitamini, karatoneid ve fenolik bileşiklerin vücutta 
karaciğer, kalp, beyin ve endokrin bezlerinin sağlıklı bir şekilde çalışmasına katkı sağlamaktadır (Chrubasik ve ark., 2006; Leahu ve ark., 2014). Kuşburnu meyvesi kurutularak, içecek yapılarak ve diğer gıda formlarına dönüştürülerek birçok şekilde tüketilebilmektedir. Kuşburnu meyvesi yoğun olarak marmelat, reçel,şarap gibi gıda türlerinin yapımının yanında pasta, ekmek ve çorba gibi gıdaların üretiminde ise yan katkı maddesi olarak kullanılmaktadır (Biçer ve Kar, 2013).

Kuşburnu meyvesi, diğer taze meyvelerde olduğu gibi taze haliyle uzun süre dayanamaz. Bu nedenle ürünleri uzun süre bozulmadan kullanabilmek için genellikle ya işlenerek ya da kurutularak saklanmalıdır. Kurutma; yüksek nem içeriğine sahip tarımsal ürünlerin uzun süre bozulmadan saklanabilmesi için uygulanan, nemin büyük bir kısmı uzaklaştırılarak ürün su aktivite değerinin düşürülerek küf, maya ve mantar gibi mikrobik canlıların üremesinin engellendiği ve aynı anda ürün içerisinde gerçekleşen bir 1s1-kütle transfer olayıdır. Bu olay ürünlere kontrollü ve kontrolsüz olmak üzere bir şekilde uygulanmaktadır.

Tarımsal ürünlerin kurutulması için üreticilerin en fazla tercih ettiği yöntemin başında güneşe sererek yapılan kurutma yöntemi gelmektedir. $\mathrm{Bu}$ yöntem az maliyetli ve pratik olması açısından çok fazla uygulanmasına rağmen, homojen nem içeriğine sahip kuru ürünlerin elde edilememektedir (Midilli, 2001; Aghbashlo ve ark., 2010; Göztok ve İçier, 2017). Bu olumsuz durumlardan dolayı ticari ve besin değeri daha yüksek ürünlerin elde edebilmek için yapay kurutucuların kullanılması kaçınılmazdır (Figiel, 2010; Karabacak ve ark., 2015). Bu kurutuculardan biri de etüv ve mikrodalga kurutuculardır. Etüv kurutma yöntemi doğal kurutma yöntemine göre ürünleri kısa sürede kuruturken bunun yanında da yüksek miktarda enerji harcamaktadır. Etüv kurutucularda kurutma havası sıcaklığı ile hızının kontrol edilebilir olması doğal kurutma yöntemine göre daha kaliteli kurutulmuş son ürünler elde edilmesine olanak sağlamaktadır. Diğer yapay kurutuculardan biri olan mikrodalga kurutucularda ise magnetronun ürettiği mikrodalga ışın üründeki su moleküllerini çok fazla sayıda titreştirerek ısıyı ürün içerisinden yüzeyine doğru taşınmasına neden olmaktadır. Mikrodalga kurutucularda gerçekleşen bu 1S1 oluşum ve taşınım şeklinden dolayı ürünler kısa sürede kurumakta ve enerji tüketimi etüv kurutuculara göre çok daha az seviyelerde olmaktadır. Ancak mikrodalga kurutucularda kurutma işleminin sonlarına doğru üründe bulunan nem seviyesi azaldığından dolayı baz kalite kayıpları oluşturmakta veüründeki keskin köşeli yerlerde ise renk kararmalarına sebep olmaktadır.

Uygun koşullarda kurutulan kuşburnu meyvelerinin kalite değerleri yüksek olmasından dolayı ürünlerin tüketicilerden tarafindan daha fazla tercih edilmekte ve ürünler piyasada daha kolay satılmaktadır. Bu nedenle kuşburnu meyveleri kurutulurken kurutma yöntemi ve koşullarının iyi belirlenmesi gerekmektedir. $\mathrm{Bu}$ çalışmada; Ülkemizde tescilli 2 çeşitten biri olan "Gerçekcioğlu" kuşburnu çeşidinin optimal hasat döneminde meyveleri kullanılmıştır. Meyveler etüv ve mikrodalga kurutucularda toplam yedi farklı kurutma uygulamaları yapılarak kurutulmuş ve kuru ürün kalite değişimleri incelenerek en uygun kurutma şartı belirlenmiştir.

\section{Materyal ve Yöntem}

\subsection{Materyal}

Çalışmada, Tokat Gaziosmanpaşa Üniversitesi genetik kaynak parselinde bulunan ve ülkemizde tescilli 2 çeşitten bir olan "Gerçekcioğlu" kuşburnu çeşidinin optimal hasat döneminde toplanan meyveleri kullanılmıştır (Anonim, 2015). Meyveler hasat edildikten sonra, kurutma işlemleri için Biyosistem Mühendisliği kurutma laboratuvarına getirilmiştir. Ürünler kurutma işlemleri sonlanana kadar $+4 \pm 0.5^{\circ} \mathrm{C}$ sıcaklığa sahip ortamda muhafaza edilmiştir. Kurutma işlemlerinde kullanılmak üzere ezik ve buruşuk meyveler ayıklanmış ve sağlam meyveler ikiye dilimlenmiştir.

\subsection{Yöntem}

\subsubsection{Meyvenin toplam su miktarl (\%)}

Kurutma işlemlerine başlanılmadan önce kuşburnu meyvesinin toplam su içeriği belirlenmiştir. Tayin işleminde başlangıç ağırlı̆̆ belli olan taze meyve parçaları $70{ }^{\circ} \mathrm{C}$ ayarlanmış etüvde belli aralıklarla çıkartılıp tartılarak ağırlık değişimi sabitlenene devam edilmiştir. Nem tayini işlemi ortalama 19 saat sürmüştür. Son ağırlıkları belirlenen örnekler ilk ağıllıklarına oranlanarak hesaplanmıştır (Yağcıoğlu, 1999).

\subsubsection{Kurutma yöntemleri}

Kurutma işlemlerinde etüv ve mikrodalga kurutma yöntemleri kullanılmıştır. Ürünler etüv kurutucuda 50 , 60 ve $70{ }^{\circ} \mathrm{C}$ kurutma havası sicaklıkları kullanılırken, mikrodalga kurutucuda ise $360,540,720$ ve $900 \mathrm{~W}$ kurutma güç değerleri kullanılmıştır. Kurutma ișlemleri üç tekerrürlü ve her tekerrürde ortalama $25 \pm 3 \mathrm{~g}$ ürün kullanılmıştır. Kurutucu içerisindeki ürünler belirli süre aralıklarında çıkartılıp \% $1 \mathrm{~g}$ hassasiyete sahip bir terazi ile tartılarak ürün su içeriği başlangıç ağırlığı dikkate alınarak \% 10-13 aralığına kadar kurutulmuştur. Etüv kurutucuda üçer defa 30 dakika, 1 saat ve 2 'şer saat aralıklarla tartım işlemi yapılırken daha sonra devamlı 3'er saat aralıklarla tartım işlemleri gerçekleştirilmiştir. Ancak 3'er saat aralıklar tartım işleminin yapıldığı aşamada ağıllık değişimi saatte bir kontrol edilerek istenilen nem aralığını yakalamaya çalışılmıştır. Mikrodalga kurutucuda ise 30 saniye de bir ağıllk değişimi kayıt edilmiştir. Ön denemeler neticesinde mikrodalga kurutma işlemlerinde 30 saniye çalıştırılıp 2 dakika dinlendirmeli şekilde kesikli (1-4) yöntemin uygun olduğuna karar verilerek ona göre uygulanmıştır. 
Kurutma işlemlerinde kullanılan sıcak havalı kabin tip etüv kurutucu, Şimşek Laborteknik marka olup ST120 tip modelidir. Kurutma havasının sicaklığını istenilen değerlere ayarlayabilmek için kurutucu üzerinde bulunan PID kontrol denetleyiciler kullanılarak yapılabilmektedir. Kurutucudaki hava sıcaklığ $30-250$ ${ }^{\circ} \mathrm{C}$ sıcaklık aralıklarına ayarlanabilme olanağı vardır. Çalışmada kullanılan ev tipi mikrodalga kurutucu Vestel marka ve MD-GD23 model olup, \% 20, 40, 60, 80 ve 100 güç kademelerine ve 10'ar saniye şeklinde artan süre değerlerine ayarlanabilmektedir. Mikrodalga kurutucu toplam $900 \mathrm{~W}$ çıkış gücüne sahip olup boyutları Yükseklik $\times$ Genişlik $\times$ Derinlik sırasıyla; 305 $\mathrm{mm} \times 508 \mathrm{~mm} \times 385 \mathrm{~mm}$ 'dir.

\subsubsection{Renk ölçümü}

Taze ve kurumuş kuşburnu meyvelerinin renk ölçümleri L, a ve b olarak ve Hue değerleri olarak, Minolta marka CR300 model renk ölçer ile yapılmıştır.

Bu değerler; " L " meyvenin parlaklık değerini ifade etmekte olup 0-100 arasında bir değer almaktadır. " a " kırmızı-yeşil, " b " ise sarı-mavi renkleri ifade etmektedir. Bu değerler+ işaretli olursa "a" kırmızıyı "b" sarı renkte olduğunu- işaretli değerler alırsa "a" yeșil ve "b" mavi renkte olduğunu ifade etmektedir (McGuire, 1992). Ölçülen $\mathrm{L}$, a ve b değerleri ürün hakkında tek başına bir anlam ifade etmezken bu değerler kullanılarak ticari renk değeri açısından önemli olan hesaplanarak belirlenen kroma, kırmızılık indeksi, hue açısı, toplam renk değişimi ve kahverengileşme indeks değerleri belirlenmiştir. $\mathrm{Bu}$ değerler bazı ren ölçüm cihazlarında doğrudan da vermektedir ancak çalışmada kullanılan renk ölçüm cihazı bu özellikte değildir.

Hesaplanan bu değerler;

Kroma değeri: Meyve renginin tonunu ifade etmekte olup solgun renklerde kroma değeri düşük canlı renklerde ise yüksek değerler almaktadır. Ürünlerin kroma değerlerini belirlerken 1 nolu eşitliği kullanarak hesapladıklarını ifade etmişlerdir (Demirhan ve Özbek, 2011; Dirim ve Talih, 2018).

$$
\mathrm{C}=\left(\mathrm{a}^{2}+\mathrm{b}^{2}\right)^{1 / 2}
$$

Kırmızılaşma indeksi: Renk ölçerle belirlenen "a" ve "b" değerinin oranlanmasıyla belirlenmektedir. Kuşburnu meyvesinin kurutma şartları altındaki kırmızılaşma değerini ifade etmektedir (Babalık ve Pazır, 1997).

Hue değeri:Üründe ölçülen "a" ve "b" değerlerinin $360^{\circ}$ 'lik bir renk dairesinde konumlandırılarak her açıya karşıllık gelen renklerin ne oldukları anlaşılmaktadır. Hue renk açısı değeri belirlenirken 2 nolu eşitlik kullanmıştır.

$$
\mathrm{Hue}^{\circ}=\tan ^{-1}\left(\frac{\mathrm{b}}{\mathrm{a}}\right)
$$

Toplam renk değişim değeri: Taze ürünün renk değerlerine göre kurutma şartları altında göstermiş olduğu renk değişim değerini ifade etmektedir. Söğütlü ve Sönmez (2006), toplam renk farklılık değerini belirlemek için 3 nolu eşitliği kullanmışlar..

$$
\Delta \mathrm{E}=\sqrt{\left(\mathrm{L}_{\mathrm{t}}-\mathrm{L}_{\mathrm{k}}\right)^{2}+\left(\mathrm{a}_{\mathrm{t}}-\mathrm{a}_{\mathrm{k}}\right)^{2}+\left(\mathrm{b}_{\mathrm{t}}-\mathrm{b}_{\mathrm{k}}\right)^{2}}
$$

Eşitliğe göre; $L_{t}, a_{t}$ ve $b_{t}$ değerleri sırasılyla taze kuşburnu meyvesinin parlaklık, kırımızı-yeşillik ve sarılık-mavilik renk değerlerini ifade ederken, $L_{k}, a_{k}$ ve $b_{k}$ değerleri ise sırasıyla kurutulmuş ürüne ait aynı renk değerlerini ifade etmektedir.

Kahverengileşme indeks değeri: Ürünün kahverengileşme indeks değerini ifade eden simge " BI " ve bu değerin hesaplanmasında ise " $\mathrm{x}$ " katsayısı değeri kullanılmaktadır. Plou ve ark. (1999)'na göre "BI" ile "x" katsayısı değerlerinin belirlenmesi için 4 ve 5nolu eşitlikleri kullanmıştır.

$$
\begin{aligned}
& \mathrm{BI}=\frac{[100(\mathrm{x}-0,31)]}{0,17} \\
& \mathrm{x}=\frac{\mathrm{a}+(1,75 \cdot \mathrm{L})}{[(5,645 . \mathrm{L})+(\mathrm{a}-(3,012 . \mathrm{b}))]}
\end{aligned}
$$

\subsubsection{C vitamin tayini $(\% \mathrm{mg} / 100 \mathrm{ml})$}

Kurutulmuş kuşburnu meyvelerinin $\mathrm{C}$ vitamin değerleri belirlenerek taze kuşburnu meyvesine göre kıyaslanmıştır. C vitamini analizinde spektrometrik yöntem kullanılmıştır (Hışıl, 2004).

\subsubsection{Istatistik analiz}

Çalışma kapsamında elde edilen renk ve vitamin C bulguları SPSS 17.0 programında işlenerek çoklu karşllaştırma testine (duncan) tabi tutulmuştur.

\section{Bulgular ve Tartışma}

\subsection{Kuruma verileri}

Kurutulmuş kuşburnu meyvesinin toplam su içeriği \% 68.31 olarak belirlenmiştir. $\mathrm{Bu}$ değer hasat sonrasında bozulmadan uzun süre saklanabilmesi için yüksek olup \% 10-13 gibi depolanabilir bir kritik toplam su seviyesine kadar kurutulması gerekmektedir. Ürüne uygulanan sıcak hava ve mikrodalga kurutma güç şartları altında ortalama kuruma süreleri belirlenmiş̧tir (Çizelge 1).

Erentürk ve ark. (2010) etüv bir kurutucu ile bütün ve dilimlenerek kuşburnu meyvesini $50,60,70$ ve $80^{\circ} \mathrm{C}$ sıcaklıklarda kurutmuşlar. Çalışmada, bütün kuşburnu meyvelerinin kurutma sıcaklıklarına bağlı olarak 
ortalama kuruma sürelerinin 30 ile 12 saat arasında değiştiğini ve dilimlenen meyvelerin kuruma sürelerinin ise 4 ile 5 saat arasında değiş̧tiğini tespit etmiştir. Demarchi ve ark. (2018) vakum kurutucuda 40, 50, 60 ve $70{ }^{\circ} \mathrm{C}$ sicaklıkları kullanarak kuşburnu kabuğu kurutma çalışması yapmışlar. Belirlenen bulgulara göre, kurutma materyalinin kuruma süresi ortalama 4 ile 8 saat arasında değiștiğini belirtmișler. Ergüneş ve Taşova (2018) etüv kurutucuda dilimlenmiş kuşburnu meyvesini 50,60 ve $70{ }^{\circ} \mathrm{C}$ sicaklıklarında kurutarak ortalama kuruma süresi ve diğer kuruma özelliklerinin araştırmışlar. Çalışma kapsamında, ortalama kuruma sürelerinin çalışlan bu çeşitle aynı sürelerde kurudukları görülmektedir.

\section{2. Renk değerleri}

Taze ve kurutulmuş kuşburnu meyvelerine ait ölçülen ve hesaplanan ortalama renk değerleri belirlenmiştir (Çizelge 2 ve 3 ).

Çizelge 2'ye göre taze kuşburnu meyvesinde ölçülen $\mathrm{L}$, $\mathrm{a}$ ve $\mathrm{b}$ değerleri kuru ürünlerde ölçülen değerlere göre sadece L değerleri istatistiksel açıdan $(p<0.05)$ bir farklılığın olmadığı görülürken, a ve b değerlerinde ise tazeye göre, istatistiksel açıdan $(p<0.05)$ farklı olduğu belirlenmiştir. Kurutulmuş ürünlerin a değerleri arasında istatistiksel açıdan $(p<0.05)$ bir farklılık oluşmazken, b değerlerinde ise farklılık $(p<0.05)$ oluşmuştur. Kurutulmuş ürünler, tazeye göre kiyaslandığında $b$ değerinin dikkate alınmasının daha uygun olacağı ön görülmüştür. Kurutulmuş ürünler $b$ değeri açısından tazeye göre kiyaslandığında ise en uygun kurutma koşullarının 360 ve $720 \mathrm{~W}$ mikrodalga güç değerleri olduğu belirlenmiştir.

Çizelge 1. Farklı kurutma koşullarında kuşburnu meyvesinin son toplam su içeriği ve kuruma süreleri

Kurutma Yöntemi $\quad$ Kurutma Şartları Toplam Son Su İçeriği (\%) Turuma Süreleri

\begin{tabular}{llll}
\hline & $50{ }^{\circ} \mathrm{C}$ & $\% 9.62$ & 16.5 saat \\
Etüv & $60{ }^{\circ} \mathrm{C}$ & $\% 10.33$ & 7.5 saat \\
& $70{ }^{\circ} \mathrm{C}$ & $\% 9.67$ & 7 saat \\
\hline \multirow{3}{*}{ Mikrodalga } & $360 \mathrm{~W}$ & $\% 10.96$ & 27 dakika \\
& $540 \mathrm{~W}$ & $\% 11.13$ & 14 dakika \\
& $720 \mathrm{~W}$ & $\% 9.80$ & 11 dakika \\
\hline
\end{tabular}

Çizelge 2. Kuşburnu meyvesine ait ölçülen renk değerleri

\begin{tabular}{lccll}
\hline Kurutma Yöntemi & Kurutma Şartları & $\mathrm{L}^{*}$ & $\mathrm{a}^{*}$ & \multicolumn{1}{c}{$\mathrm{b}^{*}$} \\
\hline Taze & - & $38.37^{\mathrm{a}} \pm 0.88$ & $24.28^{\mathrm{a}} \pm 0.63$ & $12.60^{\mathrm{a}} \pm 0.15$ \\
\hline \multirow{2}{*}{ Etüv } & $50^{\circ} \mathrm{C}$ & $37.74^{\mathrm{a}} \pm 1.02$ & $12.56^{\mathrm{b}} \pm 0.42$ & $7.08^{\mathrm{d}} \pm 0.22$ \\
& $60^{\circ} \mathrm{C}$ & $37.77^{\mathrm{a}} \pm 0.54$ & $15.76^{\mathrm{b}} \pm 0.31$ & $7.48^{\mathrm{cd}} \pm 0.11$ \\
& $70^{\circ} \mathrm{C}$ & $37.28^{\mathrm{a}} \pm 0.77$ & $15.13^{\mathrm{b}} \pm 0.14$ & $8.00^{\mathrm{bcd}} \pm 0.38$ \\
\hline \multirow{3}{*}{ Mikrodalga } & $360 \mathrm{~W}$ & $40.58^{\mathrm{a}} \pm 0.92$ & $14.67^{\mathrm{b}} \pm 0.34$ & $9.79^{\mathrm{b}} \pm 0.12$ \\
& $540 \mathrm{~W}$ & $37.04^{\mathrm{a}} \pm 1.28$ & $16.39^{\mathrm{b}} \pm 0.51$ & $9.02^{\mathrm{bc}} \pm 0.09$ \\
& $720 \mathrm{~W}$ & $38.75^{\mathrm{a}} \pm 0.49$ & $16.43^{\mathrm{b}} \pm 0.53$ & $9.78^{\mathrm{b}} \pm 0.19$ \\
& $900 \mathrm{~W}$ & $38.34^{\mathrm{a}} \pm 0.86$ & $13.77^{\mathrm{b}} \pm 0.44$ & $8.43^{\mathrm{bcd}} \pm 0.21$ \\
\hline
\end{tabular}

Bulgular $p<0.05$ önem değerine göre analiz edilmiştir.

Tazeye göre, kuru ürünler için hesaplanan en uygun kroma değeri etüv kurutucuda; 60 ve $70{ }^{\circ} \mathrm{C}$ kurutma havası sicaklığında belirlenirken, mikrodalga kurutucuda ise $720 \mathrm{~W}$ güç değerinde belirlenmiştir. En az renk değişimi, etüv kurutucuda $60{ }^{\circ} \mathrm{C}$ kurutma havası sıcaklığında bulunurken, mikrodalga kurutucuda ise 540 
W güç değerinde bulunmuştur. Çalışmada, uygulanan en düşük kurutma sicaklığı ve güç değerlerinde ise kroma ve renk değişimleri diğer uygulanan sıcaklık ve güç değerlerine göre, daha fazla uzaklaştığ görülmüştür. Bunun sebebinin, düşük kurutma sıcaklıklarında kuruma süreleri daha uzun olması ve dolayısıyla da enerjiye daha uzun süre maruz kalması renk değerlerinin daha fazla etkilendiğinden kaynaklandığı düşünülmektedir. Koyuncu ve ark. (2003)' na göre, etüv kurutucu ile 30, 40, 50, 60 ve 70 ${ }^{\circ} \mathrm{C}$ kurutma havası sıcaklıklarında kuruttukları kuşburnu meyvesinin renk değerlerine kurutma sıcaklıklarının etki ettiği ve en yüksek kurutma sıcaklığı olan $70{ }^{\circ} \mathrm{C}$ 'de tazeye göre, en uygun renk değerlerinin elde edildiğini ifade etmişler. Pirone ve ark. (2007), yaptıkları kuşburnu meyvesi kurutma çalışmasında, taze ürünün parlaklık ve sarı-mavilik değerlerinin sırasıyla; 34.06 ve 13.53 olarak ölçtüklerini ifade etmişler. Kasun (2017), Tunceli ilinde yetişen kuşburnu meyvelerinin bazı fitokimyasal özelliklerinin belirlenmesi konulu çalışmasında, meyvenin ortalama $\mathrm{L}$, a ve b değerlerini sirasiyla; 28.97-30.37, $16.42-18.38$ ve $11.90-12.83$ aralığında değiştiğini belirtmiştir. Kayran ve Doymaz Çizelge 3. Hesaplanan renk değerleri (2017)'a göre, farklı kurutma havası sıcakları kullanılarak yaptıkları kayısı posası kurutma çalışmasında, L parlaklık değeri açısından kurutma sıcaklığının artmasıyla değerin gittikçe azaldığı ve toplam renk değişim değerinin ise arttığını ifade etmişler. Polatcı ve Taşova (2017)'ya göre, sıcaklık kontrollü mikrodalga kurutucuda farklı kurutma sıcaklıklarında yaptıkları alıç kurutma çalışmasında, kurutulmuş ürünlere ait a değerlerinin tazeye göre, çok fazla uzaklaştığını ifade etmişler.

\section{3. $C$ vitamin değerleri $(\mathrm{mg} / 100 \mathrm{ml})$}

Taze ve kurutulmuş meyvelerin $\mathrm{C}$ vitamin analiz değerleri ile kuruduktan sonra tazeye göre, kaybolan \% C vitamin değerleri sırasıyla Çizelge 4 ve 5'de verilmiştir. Çizelge 4'e göre; Uygulanan sıcak hava ve mikrodalga güç değerleri ürünün $\mathrm{C}$ vitamin değerlerinde tazeye göre, istatistiksel açıdan $(p<0.05)$ bir farklılık olduğu görülmüştür. Taze kuşburnu meyvesinin $\mathrm{C}$ vitamin değerine göre, istatistiksel açıdan $(p<0.05)$ en yakın $70{ }^{\circ} \mathrm{C}$ kurutma havası sıcaklığında belirlenmiştir.

\begin{tabular}{|c|c|c|c|}
\hline Kurutma Yöntemi & \multicolumn{2}{|c|}{ Kurutma Şartları } & $\operatorname{Kroma}(\mathrm{C})$ \\
\hline \multirow[t]{2}{*}{ Taze } & \multicolumn{2}{|c|}{-} & $27.35 \pm 1.0$ \\
\hline & \multicolumn{2}{|c|}{$50^{\circ} \mathrm{C}$} & $14.42 \pm 0.8$ \\
\hline \multirow{2}{*}{ Etüv } & \multicolumn{2}{|c|}{$60^{\circ} \mathrm{C}$} & $17.44 \pm 0.8$ \\
\hline & \multicolumn{2}{|c|}{$70^{\circ} \mathrm{C}$} & $17.11 \pm 0.7$ \\
\hline \multicolumn{3}{|c|}{$360 \mathrm{~W}$} & 17.64 \\
\hline \multirow{3}{*}{ Mikrodalga } & \multicolumn{2}{|c|}{$540 \mathrm{~W}$} & 18.71 \\
\hline & \multicolumn{2}{|c|}{$720 \mathrm{~W}$} & 19.12 \\
\hline & \multicolumn{2}{|c|}{$900 \mathrm{~W}$} & 16.15 \\
\hline \multicolumn{4}{|c|}{ Çizelge 4. Belirlenen ortalama $\mathrm{C}$ vitamin değerleri } \\
\hline $\begin{array}{l}\text { Kurutma } \\
\text { Yöntemi }\end{array}$ & \multicolumn{2}{|c|}{ Kurutma Şartları } & $\begin{array}{l}\text { C Vitamini } \\
(\mathrm{mg} / 100 \mathrm{ml})\end{array}$ \\
\hline \multirow[t]{2}{*}{ Taze } & \multicolumn{2}{|l|}{-} & $972.20^{\mathrm{a}} \pm 8.89$ \\
\hline & \multicolumn{2}{|l|}{$0^{\circ} \mathrm{C}$} & $138.89^{\mathrm{d}} \pm 2.25$ \\
\hline \multirow{2}{*}{ Etüv } & $60{ }^{\circ} \mathrm{C}$ & \multicolumn{2}{|c|}{$83.98^{\mathrm{g}} \pm 2.01$} \\
\hline & \multicolumn{2}{|l|}{$0^{\circ} \mathrm{C}$} & $180.80^{\mathrm{b}} \pm 2.54$ \\
\hline \multirow{4}{*}{ Mikrodalga } & \multicolumn{2}{|l|}{$360 \mathrm{~W}$} & $103.36^{\mathrm{e}} \pm 2.11$ \\
\hline & \multicolumn{2}{|l|}{$540 \mathrm{~W}$} & $83.98^{\mathrm{g}} \pm 1.98$ \\
\hline & \multicolumn{2}{|c|}{$720 \mathrm{~W}$} & $93.02^{\mathrm{f}} \pm 2.07$ \\
\hline & \multicolumn{2}{|c|}{$900 \mathrm{~W}$} & $144.12^{c} \pm 2.78$ \\
\hline
\end{tabular}

Bulgular $p<0.05$ önem değerine göre analiz edilmiştir. 
daha yüksek olduğu ifade etmiştir. Demarchi ve ark. (2018), vakum bir kurutucu ile $40-70{ }^{\circ} \mathrm{C}$ aralıklarında değişen sıcaklıklarda kuşburnu meyvelerini kurutmuş ve sıcaklık değerlerinin $\mathrm{C}$ vitamin üzerinde etkili olduğu ve en yüksek kurutma havası sıcaklığında daha yüksek değerler aldığını ifade etmiştir. Literatürdeki benzer çalışmalarla yapılan bu çalışmadaki bulgular bazı noktalarda benzer olduğu görülürken, bazı noktalarda ise birbirlerinde farklı sonuçlar elde edildiği görülmektedir. $\mathrm{Bu}$ durum, özellikle kuşburnu meyvesinin farklı çeşitlerinin kurutulması ve farklı kurutma yöntemi ve şartlarında kurutma çalışmalarının geliştirilmesi önerilmektedir.

Çizelge 5. Tazeye göre \% kaybolan C vitamin miktarları

\begin{tabular}{lcc}
\hline $\begin{array}{l}\text { Kurutma } \\
\text { Yöntemi }\end{array}$ & $\begin{array}{c}\text { Kurutma } \\
\text { Şartları }\end{array}$ & $\begin{array}{c}\text { Kaybolan \% C } \\
\text { Vitamin Oranı }\end{array}$ \\
\hline \multirow{3}{*}{ Etüv } & $50^{\circ} \mathrm{C}$ & 85.77 \\
& $60^{\circ} \mathrm{C}$ & 91.36 \\
& $70^{\circ} \mathrm{C}$ & 81.40 \\
\hline \multirow{3}{*}{ Mikrodalga } & $360 \mathrm{~W}$ & 89.37 \\
& $540 \mathrm{~W}$ & 91.36 \\
& $720 \mathrm{~W}$ & 90.43 \\
& $900 \mathrm{~W}$ & 85.18 \\
\hline
\end{tabular}

\section{Sonuç}

Kuşburnu meyvesi içerdiği hem temel besin değerleri hem de sahip olduğu diğer biyokimyasal özellikler açısından insan sağlığ tıbbı aromatik bir bitkidir. Çalışmada etüv ve mikrodalga kurutucular kullanılarak yedi farklı kurutma şartında kurutulan 'Gerçekcioğlu' çeşidi kuşburnu meyvesinin ortalama kuruma süresi belirlendikten sonra kurutma işlemleri açısından meyvenin renk ve $\mathrm{C}$ vitamin değerleri açısından en uygun yöntem belirlenmiştir.Belirlenen verilere göre;

1) Kurutma havası sıcaklık ve mikrodalga güç değerleri ürünün kurumasında ve kalite değerlerinin değişmesinde etkili olduğu görülmüştür.

2) Yapılan kurutma işlemleri içerisinde en uzun kuruma süresi7.5 saat ile $50{ }^{\circ} \mathrm{C}$ kurutma havas1 sıcaklığında belirlenirken, en kısa kuruma süresi ise 9 dakika ile $900 \mathrm{~W}$ kurutma gücünde yapılan kurutma işlemlerinde belirlenmiştir.

3) Uygulanan tüm kurutma işlemleri içerisinde renk kriteri açısından en uygun kurutma şartlarının olarak $720 \mathrm{~W}$ veya $70{ }^{\circ} \mathrm{C}$ değerlerinin seçilmesinin daha uygun olduğu belirlenmiştir.

4) $C$ vitamin kriteri açısından tüm kurutma şartları içerisinde istatistiksel olarak $70^{\circ} \mathrm{C}$ kurutma sıcaklığının daha uygun olduğu belirlenmiştir. Yapılan bu çalışmada belirlenen bulgulara göre 'Gerçekcioğlu' kuşburnu çeşidi meyvelerinin kuruma süresi, renk ve $\mathrm{C}$ vitamin değerleri açısından $70{ }^{\circ} \mathrm{C}$ kurutma havası sıcaklığında kurutulması önerilmektedir.

\section{Kaynaklar}

Aghbashlo, M., Kianmehr, M.H., Hassan-Beygi, S.R., 2010. Drying an drehydration characteristics of sour cherry (Prunus cerasus L.). Journal of Food Processing and Preservation 34(3): 351-365.

Anonim, 2015. 'Gerçekcioğlu' Kuşburnu Çeşidi. (http://www.tarim.gov.tr/bugem/ttsm/menu/30/kayit -listeleri) (Meyve ve Asma Çeşit Listesi (Fruit/Vine).

Artik, N., Eksi, A., 1988. Studies on chemical composition of some wild fruits (Rosa canina, Crataegusmonogyna, Crataegusaronia, Vaccinium myrtillus and Berberis vulgaris). Food Industry, 9, 33-34.

Babalık, Ö., Pazır, F., 1997. Domates Kurutulmasında Kükürt Dioksit Uygulaması. G1da, 22(3): 193-199.

Biçer, A., Kar, F., 2013. Experimental Investigation of Drying Behavior of Rosehip in a Cyclone-Type Dryer. International Journal of Nutrition and Food Engineering, 7 (6).

Chrubasik, C., Duke R.K., Chrubasik, S., 2006. The evidence fo rclinical efficacy of rosehip and seed: a systematic review, PhytotherRes.

Demarchi, S.M., Irigoyen, R.M.T.,Giner, S.A., 2018. Vacuum drying of rosehip leathers: Modelling of coupled moisture content and temperature curves as a function of time with simultaneous time-varying ascorbic acid retention. Journal of Food Engineering, 233, 9-16.

Demir, F.,Özcan, M., 2001. Chemical and technologica lproperties of rosa (Rosa canina L.) fruits grown wild in Turkey. Research note. Journal of Food Engineering, 47, 333-336.

Demirhan, E.,Özbek, B., 2011. Colorchangekinetics of celeryleavesundergoingmicrowavedrying. Chemical Engineering Commun, 198(10): 1189-1205.

Dirim, S.,Talih, M., 2018. Kurutma Yardımc1 Maddelerinin Dondurarak Kurutulmuş Taflan Tozlarının Özellikleri Üzerine Etkisi, Gıda TheJournal Of Food, 43 (3): 461-475 doi: 10.15237/gida.GD17109.

Erentürk, S., Gülaboğlu, M.Ş., Gültekin, S., 2005. Experimenta ldetermination of effective moisture diffusivities of whole- andcut-rosehips in convective drying. Food and Bioproducts Processing, 88, 99104.

Ergüneş, G., Taşova, M., 2018. Kabin kurutucuda kurutulan kuşburnu (Rosa canina L.) meyvesinin kuruma performansı, efektif difüzyon ve aktivasyon enerjisi değerlerinin belirlenmesi. Akademik Ziraat Dergisi, 7(1), syf: 75-82.

Figiel, A., 2010. Drying Kinetics and Quality of Beetroots Dehydratedby Combination of Convective and Vakuum-Microwave Methods. Journal of Food Engineering, 98: 461-470.

Göztok, S.P., İçier, F., 2017. Karbon Fiber Destekli Kabin Kurutucuda Farklı Sicaklıklarda Elma Dilimlerinin Kurutulmasının İncelenmesi: Kurutma 
Karakteristikleri ve Performans Değerlendirmesi. Akademik, Gida, 15 (4).

Hış1, Y., 2004. Enstrümental gıda analizleri laboratuvar deneyleri. Ege Üniversitesi Mühendislik Fakültesi Ders Kitapları Yayın no:45, Bornova, İzmir.

Karabacak Özkan, A., Özcan Sinir, G., Suna, S., 2015. Mikrodalga ve Mikrodalga Destekli Kurutmanın Çeşitli Meyve ve Sebzelerin Kalite Parametreleri Üzerine Etkisi, U.Ü. Ziraat Fakültesi Dergisi, 29 (2), 125-135.

Kasun, Ş., 2017. Tunceli Yöresinde Yetişen Kuşburnu (Rosa canina) Ve Alıç (Crataegus Orientalis) Yabani Meyvelerinin Toplam Fenolik Madde Miktarı, Fenolik Kompozisyonu, Antioksidan Kapasitesi İle Bazı Fizikokimyasal Özelliklerinin Belirlenmesi. Munzur Üniversitesi, Fen bilimleri Enstitüsü, Gıda Mühendisliği Anabilim Dalı, Tunceli.

Kayran, S., Doymaz, İ., 2017. Determination of drying kinetics and physico chemical characterization of apricot pomace in hot-air dryer. J Therm Anal Calorim, 130:1163-1170, DOI 10.1007/s10973-0176504-0.

Koyuncu, T., Tosun, I.,Üstün, N.S., 2003. Drying Kinetics and Color Retention of Dehydrated Rosehips. Dryıng Technology, 21 (7), 1369-1381.

Leahu, A., Damian, C.,Oroian, M., Ropciuc, S., Rotaru, R., 2014. Influence of Processing on Vitamin C Content of Rosehip Fruits.Animal Science and Biotechnologies, 47 (1).
McGuire, R.G., 1992. Reporting of objective color measurements. HortScience, 27, 1254 - 1255.

Midilli, A., 2001. Determination of pistachio drying behaviour and conditions in solar drying system. International Journal of Energy Research 25(8): $715-725$.

Pirone, B.N.,Ochoa, M.R., Kesseler,A.G.,Michelis, A.D., 2007. Chemical characterizion and evoluation of ascorbic acid concentration during dehydration of rosehip, American Journal of Food Technology, 2 (5), 377-387.

Plou, E., Lopez-Malo, A.,Barbosa-Canovas, G.V.,WeltiChanes, J., Swanson, B.G., 1999. Polyphenol oxidase activitiy and color of blanced and highly drostatic pressure treated banana puree. Journal of Food Science, 64, 42-45.

Söğ̈̈tlü, C., Sönmez, A., 2006. Değişik Koruyucular İle İşlem Görmüş Bazı Yerli Ağaçlarda Uv Işınlarının Renk Değiştirici Etkisi. Gazi Üniversitesi Mühendislik-Mimarlık Fakültesi Dergisi 21(1): 151159.

Polatcı, H., Taşova, M., 2017. The Effect on Drying Characteristics and Colour Values of Hawthorn Fruit of Temperature Controlled Microwave Drying Method. Türk Tarım - Gıda Bilim ve Teknoloji Dergisi, 5(10): 1130-1135.

Yağcıoglu, A., 1999. Tarımsal Ürünleri Kurutma Tekniği. Ege Üniversitesi ziraat fakültesi yayınları No: 536. Bornova, İzmir. 